\title{
FAMILY TIME AND FAMILY STRUCTURE AS CORRELATES OF ADOLESCENTS' SELF-REGULATION IN SOME SELECTED JUNIOR SECONDARY SCHOOLS, HARARI REGIONAL STATE, ETHIOPIA
}

\author{
Amare Misganaw Mihret \\ Department of Psychology, Haramaya University \\ P. O. Box 138, Dire Dawa, Ethiopia \\ amazpsyc@yahoo.com
}

Received: $19^{\text {th }}$ December 2018/ Revised: $27^{\text {th }}$ February 2019/ Accepted: $06^{\text {th }}$ March 2019

How to Cite: Mihret, A. M. (2019). Family time and family structure as correlates of adolescents' self-regulation in some selected junior secondary schools, harari regional state, Ethiopia. Humaniora, 10(1), 81-88.

https://doi.org/10.21512/humaniora.v10i1.5188

\begin{abstract}
This research aimed to examine the relationship between family time and family structure with adolescents'self-regulation in some selected Junior Secondary Schools, Harari Regional State, Ethiopia. To run on, data were collected through selfreporting questionnaire, standardized tests from 325 students selected through systematic sampling method. The data analysis was conducted using a t-test, Pearson product moment correlation, factorial ANOVA, and multiple regression. This research indicates that adolescents have a slightly lower level of self-regulatory behavior. There is a statistically significant relationship between adolescents' self-regulation and family time, family structure, and family time activity. Family time activity especially those who have leisure or recreation time together has significantly influencing adolescence self-regulation; however, gender could not make such effect independently as well as in combination with family time activity. Moreover, among others, family time activity and family structure are found to be important predictors of adolescents' self-regulatory skills. Among the variability, family time activity significantly has added to the prediction of self-regulation, accounting for $14,8 \%$ of the variability, while, family time activity and family structure together have added $17,7 \%$ of the variability. In the end, recommendations are also made for how to properly address the gaps noted in this research.
\end{abstract}

Keywords: adolescence, self-regulation, family time, family structure

\section{INTRODUCTION}

Adolescence is the period where fundamental and extensive changes are supposed to occur in most of their biological, cognitive, psychological, and social characteristics (Lerner, 2009). In this period, the adolescents thinking becomes quite abstract (Piaget as cited in Tefera, Ahemed, \& Fentahun, 2014), self-concept and selfesteem develop (Erikson, 1968); important adulthood skills like independent decision making, engagement of social activities, interpersonal skills, adjusting oneself to different situations are acquired (Leonova, Kuznetsova, \& Barabanshchikova, 2010; Schultz \& Schultz, 2009), and the desire to be independent increase (Papalia, Olds, \& Feldman, 2004). This means it is the time when healthy identity that integrates one's ability, value, motivation and interest, and also positive evaluation of the self develop (Erikson, 1968). Among other healthy human functioning skills, one is selfregulation that involves a conscious or effortful control or the ability to willfully or voluntarily inhibit, activate, or change attention and behavior (Vohs \& Baumeister, 2004).
Self-regulation is a means of achieving one's goals through initiating, evading, inhibiting, maintaining, or modulating the occurrence, form, intensity, or duration of internal feeling states, emotion-related physiological processes, emotion-related goals, and/or behavioral concomitants of emotion (Eisenberg \& Morris, 2002). It is a skill of healthy human functioning that adolescents could develop in their time span of personal and interpersonal issues. Self-regulation is viewed as a persistent action to resist temptation or to overcome anxiety (Vohs \& Baumeister, 2004) towards achieving a goal. It encompasses any efforts by the self to alter any of one's inner states or responses for better accomplishment of a target. It can be viewed as regulating one's thoughts, emotions, impulses or appetites, and task performances into a more adaptive end (Barkley, 2004). As an adulthood skill to be developed in the time of adolescence in which failing to manage oneself may have an adverse consequence on the attainment of one's goal.

Self-regulatory skills are supposed to be affected by different factors such as neurobiological (Thompson, 2011) and socialization process (Cole, 2014; Meyer et al., 2014; 
Zimmerman \& Iwanski, 2014). This means self-regulatory skills are mediated and characterized by the family, the social, the economic, and the cultural circumstances in which adolescents are immersed (Sabatier et al., 2017; Meyer et al., 2014). To this end, a different theory like Gottfredson and Hirschi's (1990) social control theory explain that adolescent poor self-regulation is developed as a result of the failure in parental socialization; parental teaching of rules and principles of a society. This means adolescents deviant behavior and inability to manage oneself towards achieving an intended goal has resulted from the failure of parenting. Besides, Gottfredson and Hirschi (1990) have described that the presence of low self-regulation will hinder the achievement of long-term individual goals. They also argue that the elements of low self-regulation, impede educational, and occupational achievement destroy interpersonal relations and undermine physical health and economic wellbeing.

Furthermore, failure to regulate oneself, low-selfregulation, is a constellation of six elements such as the tendency to be impulsive, insensitive, physical (as opposed to mental), risk-taking/seeking, short-sighted, and nonverbal (Gottfredson \& Hirschi, 1990). These have developed in early childhood due to a lack of adequate child-rearing practices (Amare, Galata, \& Ambachew, 2018) deficient behavioral monitoring, inability to recognize deviant behavior when it occurs, and not appropriately punishing the behavior when it occurs and that it will remain relatively stable throughout life (Lewis, 1997). This indicates low selfregulation is assumed to be resulted from low family time and parental involvement in children's matters (Gottfredson \& Hirschi, 1990) which would make adolescents vulnerable to peer pressure for high risk activities like premarital sex (Diclemente et al. in Papalia Olds, \& Feldman, 2004), drug consumption and fighting (Diclemente et al. in Papalia Olds, \& Feldman, 2004) and academic dishonesty. According to Meldrum et al. (2012); Vazsonyi and Huang (2010), selfcontrol and maternal attachment are found to mutually influence one another during childhood while reduced into non-significance during adolescence.

As it has noted by Buckner, Mezzacappa, and Beardslee (2003) in Tefera, Ahemed, and Fentahun (2014), adolescents who perceive themselves and their parents as having high self-regulation skills find to have lower levels of internalizing behavior problems (depression or anxiety) than peers low in these skills. Likewise, parental selfregulatory skills are supposed to influence their offspring's emotion regulation through fathers and mothers contribute differently (Barlola, Gullono, \& Hughes, 2011). The quality of parenting and the context of the parent-child relationship, if supporting, are positively linked to self-regulation behavior during early adolescence (Moilanen, Shaw, \& Fitzpatrick, 2010). Furthermore, teens who have enjoyed good parental, peer, and romantic relationship are found to have higher self-regulation than those who have not (Farley \& Kim-Spoon, 2014). On the other hand, from social learning theory perspective, Bandura's (1977) explanation of reciprocal determinism also works to adolescent's selfregulation in which the environment makes them and vice versa. In accordance with this, it has noted that adolescents' perceived self-efficacy of regulating their negative and positive effect is related to lower levels of depression, delinquency, and antisocial behaviors (Fry et al., 2012).

In fact, there is an individual difference in the ability to regulate oneself in different aspects of life. People all are not alike, as much the number of people who have an impressive capacity for self-regulation, there are also people who lose control of their behavior in a wide variety of circumstances. A failure in regulating one's emotionrelated behaviors, emotion-related physiological responses, and emotion-related goals have accompanied with poor psychological outcomes (Gottfredson \& Hirschi, 1990). Numerous factors might be attributed for the development one's capacity of self-regulation, for instance, socioeconomic, cultural, and familial (Amare, Ambachew, \& Galata, 2018; Farley \& Kim-Spoon, 2014; Chong et al., 2013) are some.

Empirical findings have reported that the quality relationship adolescents have with parents, peers, friends, and romantic relationships determine their self-regulatory ability (Farley \& Kim-Spoon, 2014). Similarly, adults support, regulation, and any other forms of bonds to different community organizations are likely to promote adolescents self-regulation (Mesten in Tefera, Ahemed, \& Fentahun, 2014). In addition, the children's behavioral problems, as reported in Van As and Janssens (2002), are related to a lack of parental support, an imbalanced parent-child relationship, a lack of cohesion and structure in the family, and poor quality communication between parents and children. This might be because of being in such a relationship gives an opportunity to see things from different perspectives and also to take responsibility in the faces of others.

Furthermore, family structure is found to have an effect on adolescents emotion regulation in favor of intact family (Dawson in Papalia, Olds, \& Feldman, 2004; Johnson, Hoffman, \& Gerstein in Papalia, Olds, \& Feldman, 2004). In fact, the role of parents in the life of children is indispensable (Morgan et al., 2012; Van As \& Janssens, 2002; George \& Rajan, 2012). They could spend a great deal of time involved their children's staffs for the development of high self-regulatory behaviors (Gottfredson \& Hirschi, 1990) so that they would not be easily prone to peer pressure and engaged in high-risk activities like premarital sex, drug consumption, and fighting (Papalia, Olds, \& Feldman, 2004). Whereas, failure to have supportive and caring adults at home and school cause adolescents to have poor self-regulatory behaviors like suicide and self-harm (Pisani et al., 2012).

Regarding gender difference in self-regulation, works of literature have shown some inconsistent findings. For instance, noted that females have better self-regulatory behaviors than males (Gottfredson \& Hirschi, 1990; Amare, Galata, \& Ambachew, 2018; Tefera, Ahemed, \& Fentahun, 2014) while Tittle et al. in Papalia, Olds, and Feldman (2004) have reported no significant difference in it. According to Pascual et al. (2012), the female is better self-regulatory behavior in and male adolescents are also found to have statistically significant differences in their self-regulatory behaviors as regards frequency of negative emotions, difficulty identifying and describing emotions, primary control engagement coping, involuntary engagement responses, and wishful thinking, while the male is good as regards the frequency of positive emotions and secondary control engagement coping. In addition, for female adolescents, maternal behavioral control is significantly and positively related to limited access to selfregulatory strategies, and difficulties are engaging in goaldirected behavior (Neuman \& Koot, 2011; Neuman et al., 2011).

From the works of literature reviewed so far, it might be possible to take a firm stand regarding the factors contributing to the development of adolescents' self- 
regulation in Ethiopia. In this regard, research findings indicate that adolescents are engaged in risky behaviors like early age sexual engagement, drug, and substance abuse (Tefera \& Mulatie, 2014) that causes them to suffer from HIV/AIDS, unplanned pregnancy, and abortion research findings. However, the role of family time activities on adolescents' self-regulation is not particularly examined in Ethiopian context and family time activities. Therefore, there is a need to investigate if self-regulatory behavior can be lower among adolescent students in Harar and if the associated factors (age, gender, family time, family time activities, and family structure) would operate similarly in the Ethiopian (Harar) context.

Therefore, this research tries to answer the following research questions; what are the status of family time and adolescents' self-regulation? Is there any statistically significant relationship between family time and adolescents' self-regulation? What are the main effects and interaction effect of family time activities and gender on adolescents' self-regulation? To what extent do gender, family structure, family time activities, and family time predict adolescents' self-regulation?

\section{METHODS}

This research is a correlational type of research design that involves quantitative data collection procedures and data analysis. The target population of this research is grade seven and eight students who are enrolled and attending classes in 2017/18 academic years. This research involves both systematic and simple random-lottery methods to select participants. In order to select the schools, among others, simple random lotter method is carried out. Thus, the research is conducted in randomly selected junior secondary schools such as Shekib Abdulahi, Ras Mekonnen, and Bethlehem primary schools in Harari Regional state, Ethiopia. These schools are composed of a total of 2571 students (1240 males and 1331 females).

In order to select individual participants, consulting Krejcie and Morgan's (1970) recommendation of sample size determinations, 333 students are selected using a systematic sampling method. Systematic sampling is used once after having and sorting out from "A to Z" the list of students based on their alphabet in the three schools selected so far. In fact, final data analysis is made based on 325 students who provide complete data in the self-reporting questionnaire. This means that eight filled questionnaires are reduced because they are incomplete. In order to measure this research, it uses one researcher that makes a questionnaire to measure the socio-demographic variables and two widely used questionnaires such as Ellington's (2011) family type scale and Grasmick et al. (1993) selfregulation scale.

For family time scale, it is the adapted scale from Ellington (2011) that has been used in her thesis. Originally, the scale is an English version composed of 23-items that are rating how much time the families spend together. In the process of adapting the scale, first, forward and backward translation is used from English into Amharic (the participants' language), and then from Amharic into English to check the validity of the instrument. Then, a pilot test is made to check the validity and reliability of the scale. Finally, the 20 items with five-point Likert scale (ranging from 1-never to 5-always) is produced that asks participants to rate how often certain activities occur in the family's household, such as expressing affection, eating meals, parent and child going to the park, singing together, or participating in outdoor activities together. The internal reliability index of the scale is found to be Cronbach Alpha of 0,78 . Besides, there is also an open-ended item that is prepared to assess the common family time activity in a family household.

A Grasmick and his colleagues' 24 item selfregulation scale are adapted to measure the self-regulatory behavior of adolescents. The scale is comprised of six subscales with four items in each. All the 24 items are scored on a four-point Likert scale ranging from; (1) strongly disagree, (2) disagree somewhat, (3) agree somewhat, and (4) strongly agree, in which agreeing to many of these items would indicate low self-control or, in other words, higher scores would mean a lack of self-control. The original Grasmick et al. (1993) scale is first translated into the local language, and an attempt is made to contextualize the intent of the items to make it more understandable. To check the internal reliability of the scale, a pilot test is computed, and the result indicates all the sub-scales and the general scale are all above a Cronbach Alpha of 0,79 .

\section{RESULTS AND DISCUSSIONS}

This section has two major subsections. The first subsection begins by presenting the background information of the participants. Following this, the level of adolescents' self-regulation and its dimensions are presented. Next, associated factors are to be examined. Then, two way ANOVA results that are computed to examine the main and interaction effect of gender and family structure on adolescent's self-regulation is presented. Finally, attempts are made to identify the most significant factors that make a significant independent contribution in predicting selfregulatory behavior are presented. In the second subsection, an attempt is also made to substantiate the findings of this research with the already uncovered body of knowledge.

Background of participants can be seen in Table 1 . $54,86 \%$ of the participants are girls, and the rest are boys, and their average age is 14,47 with the standard deviation of 1,079 . Regarding the family background, $51 \%$ of the participants are from intact family while others are from non-intact family types. On the other hand, among the family time activities, recreation is the most pleasant family time activity to children that they are enjoying with parents as indicated by $46 \%$ of participants.

Table 1 Descriptive Summary of the Variables $(\mathrm{N}=325)$

\begin{tabular}{lcccc}
\hline \multicolumn{1}{c}{ Variables } & Min & Max & Mean & $\begin{array}{c}\text { Std. } \\
\text { Deviation }\end{array}$ \\
\hline $\begin{array}{l}\text { Gender (=1, if male }= \\
0, \text { if female) }\end{array}$ & 0 & 1 & 0,41 & 0,492 \\
$\begin{array}{l}\text { Grade level (=1, if 7 } \\
=0, \text { if } 8)\end{array}$ & 0 & 1 & 0,51 & 0,501 \\
$\begin{array}{l}\text { Family structure (=1, } \\
\text { if Nuclear, =0, if non- } \\
\text { intact) }\end{array}$ & 0 & 1 & 0,51 & 0,501 \\
$\begin{array}{l}\text { Family time activity } \\
\text { (=1, Recreation, }=0,\end{array}$ & 0 & 1 & 0,46 & 0,499 \\
$\begin{array}{l}\text { if non-recreation) } \\
\text { Age }\end{array}$ & 12 & 20 & 14,47 & 1,079 \\
\hline
\end{tabular}


The level of family time and self-regulation is the researcher's major interest to determine the status of family time among the participants using one sample t-test. The result in Table 2 shows that the participants have significantly lower family time $\left(\mathrm{t}_{324}=-7,136, p>0,000\right)$ to spend with their parents. The test statistics summarize in the same table also yielded that there is a slightly lower level of self-regulation score among the participant $\left(\mathrm{t}_{324}=-\right.$ $4,295, P<0,000)$ compared to the expected mean. The result indicates that participants have lower self-regulatory behavior as higher score in self-regulation indicating low regulatory skills.

Self-regulation is conceptualized based on its six important dimensions such as impulsivity, simple task, risk seeking, physical activities, self-centered, and temper. As summarized in Table 3, a statistically significant difference is observed in the participants' score of self-centered $\left(\mathrm{t}_{324}\right.$ $=-7,542, P>0,000)$ and risk seeking $\left(\mathrm{t}_{324}=-4,824, P>0,000\right)$ that are indicating higher regulatory skills in these regard. Whereas, higher scores note in impulsivity $\left(\mathrm{t}_{324}=10,276\right.$,
$P>0,000)$, simple task $(\mathrm{t} 324=5,003, P>0,000)$, physical activities $\left(\mathrm{t}_{324}=3,048, P>0,002\right)$ and temper $\left(\mathrm{t}_{324}=4,143, P>\right.$ $0,000)$ that indicates lower regulatory skills.

In order to examine the inter-correlation among variables Pearson Product moment correlation is conducted, and the results are presented in Table 4 . The results reveals self-regulation has statistically significant relationships with family time activity $\left(\mathrm{r}_{324}=-0,385, p<0,01\right)$ favoring participants who have recreational activities with parents; family structure $\left(\mathrm{r}_{324}=-0,245, p<0,05\right)$, and family time $\left(r_{324}=-0,221, p<0,01\right)$. Another very important finding that seeks the researcher's attention is the relationship of variables like age $\left(\mathrm{r}_{324}=-0,368, p<0,01\right)$; grade level $\left(\mathrm{r}_{324}=\right.$ $-0,498, p<0,01)$ with family time. The result indicates that as the age and grade level of the participants increases the amount of time, the families supposed to spend together likely becomes decreased.

As can be seen from Table 5, the average selfregulation scores of participants who have recreation as a family time activity are a bit higher than those who have

Table 2 One Sample t-test of the Family Time and Adolescents' Self-Regulation Scores (N=325)

\begin{tabular}{lccccccccc}
\hline \multicolumn{1}{c}{ Variables } & No. of items & Scale points & Expected mean & Min & Max & Mean & SD & t-value & Sig. \\
\hline Family time & 20 & 5 & 60 & 31 & 86 & 54,26 & 14,513 & $-7,136$ & 0,000 \\
Self-regulation & 24 & 4 & 60 & 34 & 84 & 61,54 & 8,808 & 3,149 & 0,002 \\
\hline
\end{tabular}

Table 3 One Sample t-test on the Dimensions of Self-Regulation Scores (N=325)

\begin{tabular}{lccccccccc}
\hline \multicolumn{1}{c}{ Variables } & No. of items & Scale points & Expected mean & Min & Max & Mean & SD & t-value & Sig. \\
\hline Impulsivity & 4 & 4 & 10 & 6 & 16 & 11,27 & 2,136 & 10,276 & 0,000 \\
Simple task & 4 & 4 & 10 & 4 & 16 & 10,61 & 2,184 & 5,003 & 0,000 \\
Risk Seeking & 4 & 4 & 10 & 4 & 16 & 9,32 & 2,541 & $-4,824$ & 0,000 \\
Physical activities & 4 & 4 & 10 & 5 & 16 & 10,83 & 2,073 & 7,226 & 0,000 \\
Self-centered & 4 & 4 & 10 & 4 & 16 & 8,79 & 2,898 & $-7,542$ & 0,000 \\
Temper & 4 & 4 & 10 & 4 & 16 & 10,72 & 1,842 & 7,078 & 0,000 \\
\hline
\end{tabular}

Table 4 Correlations Among Variables of Interest

\begin{tabular}{|c|c|c|c|c|c|c|c|}
\hline Variables & 1 & 2 & 3 & 4 & 5 & 6 & 7 \\
\hline $\operatorname{Age}^{1}$ & 1 & & & & & & \\
\hline Gender $^{2}\left(\right.$ male $^{1}$ female $\left.^{0}\right)$ & 0,095 & 1 & & & & & \\
\hline Grade level $^{3}$ & $0,585 * *$ & 0,046 & 1 & & & & \\
\hline $\begin{array}{l}\text { Family activity }{ }^{4}(=1 \text {, if recreation }=0 \text {, if non- } \\
\text { recreation) }\end{array}$ & $-0,210 * *$ & $-0,030$ & $-0,248 * *$ & 1 & & & \\
\hline Family structure $^{5}(=1$, if intact $=0$, if non- intact $)$ & $-0,155^{* *}$ & 0,076 & $-0,225 * *$ & $-0,202 * *$ & 1 & & \\
\hline Family time $^{6}$ & $-0,368 * *$ & 0,015 & $-0,498 * *$ & $0,359 * *$ & $0,365 * *$ & 1 & \\
\hline Self-regulation ${ }^{7}$ & 0,074 & $-0,032$ & 0,060 & $-0,385^{* *}$ & $-0,245^{*}$ & $-0,221 * *$ & 1 \\
\hline
\end{tabular}

**Correlation is significant at the 0.01 level (2-tailed).

*Correlation is significant at the 0.05 level (2-tailed). 
non-recreation activities (such as task-based and meal time). However, almost no difference is observed among male and female self-regulation scores.

In order to scrutinize whether the difference in selfregulatory behavior observed so far in Table 5 significant and examine the main and interaction effect of variables, factorial ANOVA is computed. As the results shown in Table 6, statistically significant difference $\left(\mathrm{F}_{(1,324)}=55,008\right.$, $p=0,000)$ is only seen on adolescent's self-regulatory behavior score of participants' who have recreation as family time activity $(M=57,88)$ and non-recreation activity $(M=64,67)$ in favor of recreation as lower score indicates high regulatory behavior. The result suggests that family time activity really has an effect on adolescents' psychosocial functioning. Whereas, gender as a main effect and with family time activity could not produce independent and interaction effect on adolescents' self-regulatory behavior.

Multiple regression is conducted to determine the contribution of all the predictor variables on self-regulatory behavior. It is found that about $18,1 \%(\mathrm{R} 2=0,181)$ of the variance in self-regulatory behavior is explained by all the predictors together. In fact, the test of beta weights indicates among others, family structure $\left.\left(\mathrm{F}_{(3,324)}\right)=14,085, p<0,004\right)$ and family time activity $\left.\left(\mathrm{F}_{(3,324)}\right)=14,085, p<0,000\right)$ makes a significant contribution in self-regulatory behavior (Table 7).

Stepwise multiple regression is performed to determine the contribution of the variables entered in the above analysis as a predictor of self-regulation. Accordingly, family time activity adds significantly to the prediction of self-regulation $(F 1,324=56,254, p<0,000)$, accounting for $14,8 \%(R 2=0,148)$ of the variance. The addition of family structure $(F 2,324=34,691, p<0,000)$ to the original equation (family time activity) adds significantly to the prediction of self-regulation, accounting for $17,7 \%(R 2=0,177)$. The first and second entry goes to family structure and family time activity; accounting about $17,7 \%$ of the variance. Hereafter, the results of the research are discussed based on the

Table 5 Male and Female Adolescents' Self-regulation Scores by their Family Time Activities

\begin{tabular}{|c|c|c|c|c|c|c|c|c|c|}
\hline \multirow[t]{3}{*}{ Gender } & \multicolumn{6}{|c|}{ Family Time Activity } & \multicolumn{3}{|c|}{ Total } \\
\hline & \multicolumn{3}{|c|}{ Recreation } & \multicolumn{3}{|c|}{ Non-Recreation } & \multirow[b]{2}{*}{$\mathbf{N}$} & \multirow[b]{2}{*}{$M$} & \multirow[b]{2}{*}{$S D$} \\
\hline & $\mathbf{N}$ & $M$ & $S D$ & $\mathbf{N}$ & $M$ & $S D$ & & & \\
\hline Male $^{1}$ & 59 & 57,27 & 7,687 & 74 & 64,32 & 8,318 & 133 & 61,20 & 8,752 \\
\hline Female $^{0}$ & 91 & 58,27 & 8,728 & 101 & 64,93 & 7,760 & 192 & 61,78 & 8,862 \\
\hline Total & 150 & 57,88 & 8,322 & 175 & 64,67 & 7,983 & 325 & 6,54 & 8,808 \\
\hline
\end{tabular}

Table 6 ANOVA Summary of the Variance of Family Time Activity and Gender on Adolescents' Self-Regulation

\begin{tabular}{lllllc}
\hline \multicolumn{1}{c}{ Source } & Sum squares & $\boldsymbol{d f}$ & Mean squares & $\boldsymbol{F}$ & $\boldsymbol{p}$ \\
\hline Corrected Model & $3790,245^{\mathrm{a}}$ & 3 & 1260,082 & 18,940 & 0,000 \\
Family time activity & 3659,782 & 1 & 3659,782 & 55,008 & 0,000 \\
gender & 50,471 & 1 & 50,471 & 0,759 & 0,384 \\
Family time activity * gender & 3,072 & 1 & 3,072 & 0,046 & 0,830 \\
Error & 21356,524 & 321 & 66,531 & & \\
\hline Total & 25136,769 & 324 & & & \\
\hline
\end{tabular}

Table 7 Results of Multiple Regression

\begin{tabular}{lcccccc}
\hline \multicolumn{1}{c}{ Effects } & Standardized coefficients (Beta) & $\boldsymbol{R}^{2}$ & $\boldsymbol{F}$ & $\boldsymbol{D} \boldsymbol{f}$ & $\boldsymbol{t}$ & $\boldsymbol{p}$ \\
\hline On Self-Regulation & - & 0,181 & 14,085 & $5,319,324$ & 9,888 & 0,000 \\
Of Age & $-0,040$ & & & & $-0,735$ & 0,463 \\
Of Gender & $-0,026$ & & & & $-0,507$ & 0,613 \\
Of family structure & $-0,160$ & & & & $-2,917$ & 0,004 \\
Of family time activity & $-0,343$ & & & & $-6,263$ & 0,000 \\
Of family time & $-0,054$ & & & $-0,897$ & 0,371 \\
\hline
\end{tabular}


sequence of the aforementioned research questions raised.

The average age of participants is 14,47 years old in which they probably are placed in the developmental time table of early adolescence (Santrock, 2014). This is, obviously, the period where children experience sudden growth spurt as the result of genes and hormones (Santrock, 2014). With regard to the first research question, this research evidence that adolescents' self-regulatory behavior is slightly lower. In fact, high self-regulatory behaviors are observed on the two dimensions such as risk-seeking and self-centered, though, the overall status of adolescents' selfregulatory behavior is found to be slightly lower including in the four remaining dimensions (impulsivity, simple task, physical activity, and temper). This could be attributed to different factors including biological and psychosocial factors.

Alongside biological factors, environmental factors are believed to have a significant effect on adolescents' emotion, thought, and behavior. For instance, Graber, Brooks-Gunn, and Warren in Santrock, 2014) have noted that negative life events mediate links between hormones (estradiol and an adrenal hormone) and aggression in 10to 14-year-old girls. In fact, consistent findings evident that compared to middle adolescents, early adolescents assert their opinions through interruptions and immature behavior (Grotevant in Steinberg, Vandell, \& Bronstein, 2011) and age-specific increases and decreases in many emotion regulation strategies were reported (Zimmerman \& Iwanski, 2014). Similarly, Stallar et al. (2013) have noted that selfharm in young adolescents is common and can be persistent.

The role of family or parents is indispensable so far as adolescents' self-regulation is concerned. In this regard, different empirical findings evident that teens who have enjoyed good parental, peer, and romantic relationship are found to have higher self-regulation than those who have not (Farley \& Kim-Spoon, 2014). Likewise, Van As \& Janssens (2002) have reported that children's behavioral problems are caused by parental errors. The role of parents in the life of children is indispensable (Vanas \& Janssens, 2002; George \& Rajan, 2012) that they could spend a great deal of time involving their children's staffs for the development of high self-regulatory behaviors (Gottfredson \& Hirschi, 1990; Cole, 2014; Thompson, 2011). So that they would not be easily prone to peer pressure and engaged in highrisk activities like premarital sex, drug consumption, and fighting (Papalia, Olds, \& Feldman, 2004). To this end, the lower level of self-regulatory behavior in early adolescents could also be attributed to the lower level of family time adolescents have with their family.

In due course, as noted in this research in which the status of parents and children time together are also found to be slightly lower where an increased level of family time is more likely to increase the level of adolescents' selfregulatory behavior. This might be because of different factors that young adolescents avoid having time with their parents. For instance, as described in Papalia, Olds \& Feldman (2004), children in the period of adolescence develop the sense of capability to handle matters pertaining to their life and therefore disrupt family decision (Graber, Brooks-Gunn, \& Warren in Santrock, 2014). It might also be because of avoiding quarrel and nagging that is mostly occurred in early adolescence due to the fact that children begin to play a more forceful role in the family while parents do not yet acknowledge their age (Steinberg, Vandell \& Bronstein, 2011). This means it might be for the adolescents' preference to be independent and instead have more time with their age mates. In contrast, it might also be because of parents' perception of their role is less important especially when the language of their children changed and demand independence. This time, young adolescents will be exposed to peer influence which will probably lead them into easily influenced to fit the lower level of self-regulatory behavior as of their peers (Gardner, Dishion, \& Connel, 2008).

As regard to relationships among variables of interest, Tubbs, Roy, and Burton (2005) have noted that close relationships between parents and children develop through their shared participation in everyday routines, such as when they eat meals together or do household chores. It is due to the fact that is having family time together in either of meals, leisure or routines that promote well-being by giving parents and children the opportunity to talk about important matters, provide support to each other, and reinforce shared values (Cole, 2014; Fiese, Foley, \& Spagnola, 2006; Ochs \& Shohet, 2006).

In relation to family time activity and gender, similar to the current research, findings have noted that gender does not make any statistically significant difference (Tittle et al. in Papalia, Olds, \& Feldman, 2004) while family time activity has found to make a difference in adolescents' selfregulatory behavior. In this respect, inconsistencies are observed among finding some by Neuman \& Koot (2011); Tefera, Ahemed, and Fentahun (2014); Gottfredson and Hirschi (1990); Neuman et al. (2011). They have unveiled that gender does really make a difference in self-regulation. On the other hand, as noted in this research, the more the families have meal, leisure, and other time together to do activities and receive order, the greater the likelihood of adolescents' to have higher self-regulatory behavior (Cole, 2014; Fiese, Foley, \& Spagnola, 2006; Ochs \& Shohet, 2006). Especially, it is among the different types of family time activities, in recreation that adolescents are more likely to have higher self-regulatory behavior than in other activities. Even though, family time activity especially recreation is found to produce a significant contribution on adolescents' self-regulatory behavior, whereas, the combination of family time activity and gender could not be able to produce any input.

Among the variabilities in adolescents' selfregulation, $18,8 \%$ are accounted for family time and family structure. In support of this research, family structure has found to have an effect on adolescents emotion regulation in favor of intact family (Dawson in Papalia, Olds, \& Feldman, 2004; Johnson, Hoffman, and Gerstein in Papalia, Olds, \& Feldman, 2004). Unlikely, Tefera, Ahemed, and Fentahun (2014) have stated that family structure could not be significantly related to self-regulation.

\section{CONCLUSIONS}

In conclusion, the participants in this research have a slightly lower level of self-regulatory behavior. Similarly, the lower self-regulatory behavior is also observed in the four dimensions of self-regulation such as in impulsivity, simple task, physical activity, and temper, whereas, a slightly higher level of self-regulatory behavior has observed in the two remaining dimensions (risk seeking and self-centered). The higher level of family time is the greater the likely of higher self-regulatory behavior adolescents' to have. Furthermore, family time activities and family structure have found to be the most important variables that account 
$18,8 \%$ of the variability on self-regulation. It is leisure time or recreation that is an important family time activity than others. Therefore, in order to safeguard from the adverse effect of having low-income family time activity, it would be advised families to have a greater deal of time with their children that would give them a chance to discuss, support each other, and adolescents have higher self-regulatory behavior. Finally, the researcher would advise researchers to conduct an extensive study using a mixed approach that involves parents, students, and schools to introduce wider variability in the nature data and sample characteristics.

\section{ACKNOWLEDGEMENT}

First and for most, I would like to extend my gratitude for school directors who helped me in collecting necessary data from students and their welcoming attitude. In addition, my heart felt appreciation goes to Mr. Galata Sitota and Hana Tadesse for the proofreading of the manuscript and coding data. It was because of your support that I am able to develop this manuscript.

\section{REFERENCES}

Bandura, A. (1977). Social learning theory. New Jersey: Prentice Hall.

Barkley, R. A. (2004). Attention-deficit/hyperactivity disorder and self-regulation: Taking an evolutionary perspective on executive functioning. In R. F. Baumeister and K. D. Vohs (Eds.), Handbook of SelfRegulation: Research, Theory, and Applications (pp. 301-323). New York: Guilford Press.

Barlola E., Gullono, E., \& Hughes, E. K. (2011). Child and adolescent emotion regulation: The role of parental emotion regulation and expression. Clinical Child and Family Psychology Review, 14(2), 198-212. doi: 10.1007/s10567-011-0092-5.

Buckner, J. C., Mezzacappa, E., \& Beardslee, W. R. (2003). Characteristics of resilient youths living in poverty: The role of self-regulatory processes. Development and Psychopathology, 15(1), 139-162. doi: 10.1017. S0954579403000087.

Chong, S. T., Teh, P. S., Jaafar, J. R., Rahim, S. A., Subhi, N., Kadir, N.A., Hoesni, S. M., Mohamad, S. M., Nen, S., Sarnon, N. (2014). Caring or controlling? Parental monitoring and its effect on negative emotion and achievement motivation of at-risk adolescents. Procedia Social and Behavioral Science, 140, 270273. doi: 10.1016/j.sbspro.2014.04.419.

Cole, P. M. (2014). Moving ahead in the study of the development of emotion regulation. International Journal of Behavioral Development, 38(2), 203-207. doi: $10.1177 / 0165025414522170$.

Eisenberg, N., \& Morris, A. S. (2002). Children's emotionrelated regulation. In R. V. Kail (Ed.), Advances in Child Development and Behavior (Vol. 30, pp. 90229). Amsterdam: Academic Press.

Ellington, A. S. (2011). The role of family time on a young child's overall development (Master Thesis). Alabama: University of Alabama.

Erikson, E. H. (1968). Identity: Youth and crisis. New York: Norton \& Company.

Farley, J. P., \& Kim-Spoon, J. (2014). The development of self-regulation: Reviewing the role parent, peer, friends, and romantic relationships. Journal of Adolescence, 37(4), 433-440. http://dx.doi. org/10.1016/j.adolescence.2014.03.009.

Fiese, B. H., Foley, K. P., \& Spagnola, M. (2006). Routine and ritual elements in family mealtime: Contexts for child well-being and family identity. New Directions for Child and Adolescent Development, 111, 67-89. doi:10.1002/cd.156.

Fry, M. D., Guivernau, M., Kim, M. S., Newton, M., Gano-Overway, L. A., Magyar, T. M. (2012). Youth perceptions of a caring climate, emotional regulation, and psychological wellbeing. Sport Excersise and Performance Psychology, 1(1), 44-57.

Gardner, T. W., Dishion, T. J., \& Connell, A. M. (2008). Adolescent self-regulation as resilience: Resistance to antisocial behavior within the deviant peer context. Journal of Abnormal Child Psychology, 36(2), 273284. doi: 10.1007/s10802-007-9176-6.

George, S., \& Rajan, A. (2012). Factors of child rearing practices: Qualitative analysis. Journal of Psychology, 3(2), 99-10.

Gottfredson, M., \& Hirschi, T. (1990). A general theory of crime. Stanford: Stanford University Press.

Grasmick, H. G., Tittle, C. R., Bursik, Jr., R. J., \& Arneklev, B. J. (1993). Testing the core empirical implications of Gottfredson and Hirschi's general theory of crime. Journal of Research in Crime and Delinquency, 30(1), 5-29

Krejcie, R. V., \& Morgan, D. W. (1970). Determining sample size for research activities. Educational and Psychological Measurement, 30, 607-610,

Leonova, A. B., Kuznetsova, A. S., \& Barabanshchikova, V. V. (2010). Self-regulation training and prevention of negative human functional states at work: Traditions and recent issues in Russian applied research. Psychology in Russia: State of the Art, 3, 482-507. Moscow: Lomonosov Moscow State University.

Lerner, R. M. (2009). The positive youth development perspective: Theoretical and empirical bases of a strengths-based approach to adolescent development. In C. R. Snyder \& S. J. Lopez (Eds.), Oxford Handbook of Positive Psychology (pp. 149-164). Oxford: Oxford University Press.

Lewis, R. (1997). The discipline dilemma (2 ${ }^{\text {nd }}$ Ed.). Melbourne: The Australian Council for Educational Research Ltd.

Meldrum, R. C., Young, J., Hay, C., Flexon J. L. (2012). Does self-control influence maternal attachment? A reciprocal effects analysis from early childhood through middle adolescence. Journal of Quantitative Criminology, 28(4), 673-699. doi: 10.1007/s10940012-9173-y.

Meyer, S., Raikes, H. A., Virmani, E. A., Waters, S., \& Thompson, R. A. (2014). Parent emotion representations and the socialization of emotion regulation in the family. International Journal of Behavioral Development, 38(2), 164-173. doi: $10.1177 / 0165025413519014$.

Mihret, A. M., Asfaw, A. T., \& Dilgasa, G. S. (2018). Adolescents' perceived parental childrearing practice and its effect on their psychosocial functioning in some selected secondary schools of East Hararghe Zone, Ethiopia. International Journal of Education and Literacy Studies(IJELS), 6(3), 37-46. doi: http:// dx.doi.org/10.7575/aiac.ijels.v.6n.3p.37.

Moilanen, K. L., Shaw, D. S., \& Fitzpatrick, A. (2010). Selfregulation in adolescence: Relations with mother-son 
relationship quality and maternal regulatory support and antagonism. Journal of Youth and Adolescence, 39(11), 1357-1367. doi: 10.1007/s10964-0099485-x.

Morgan, Z., Brugha, T., Fryers, T., \& Stewart-Brown, S. (2012). The effects of parent-child relationships on later life mental health status in two national birth cohorts. Social Psychiatry and Psychiatric Epidemiology, 47(11), 1707-1715. doi: 10.1007/ s00127-012-0481-1.

Neuman, A. \& Koot, H. M. (2011). Emotion regulation difficulties in adolescents: Associations with parenting and mother-adolescent relationship quality. Zeitschrift für Entwicklungs psychologie und pädagogische Psychologie, 43, 153-160. doi: 10.1026/0049-8637/a000043.

Neumann, A., Van Lier, P. A., Frijns, T., Meeus, W., \& Koot, H. M. (2011). Emotional dynamics in the development of early adolescent psychopathology: A one-year longitudinal study. Journal of Abnormal Child Psychology, 39(5), 657-669. doi: 10.1007/ s10802-011-9509-3.

Ochs, E., \& Shohet, M. (2006). The cultural structuring of mealtime socialization. New Directions for Child and Adolescent Development, 111, 35-49. doi:10.1002/ cad.153.

Papalia, D. E., Olds, S. W., \& Feldman, R. D. (2004). A child world: Infancy through adolescence. Boston: McGraw Hill.

Pascual, A., Etxebarria, I., Ortega, I., \& Ripalda, A. (2012). Gender differences in adolescence in emotional variables relevant to eating disorders. International Journal of Psychology and Psychological Therapy, 12(1), 59-68.

Pisani, A. R., Wyman, P. A., Petrova, M., SchmeelkCone, K., Goldston, D. B., Xia, Y., \& Gould, M. S. (2012). Emotion regulation difficulties, youthadult relationships, and suicide attempts among high school students in underserved communities. Journal of Youth Adolescence, Springer Science Business, 42(6), 807-820. doi: 10.1007/s10964-0129884-2.

Sabatier, C., Cervantes, D. R., Torres, M. M., De los Rios, O. H., \& Sañudo, J. P. (2017). Emotion regulation in children and adolescents: Concepts, processes, and influences. Psicología Desde El Caribe, 34(1), 101110.

Santrock, J. W. (2014). Adolescence (5 ${ }^{\text {th }}$ Ed.). New York: McGraw-Hill.
Schultz, P. D., \& Schultz, S. E. (2009). Theories of personality ( $9^{\text {th }}$ Ed.). Belmont: Michele Sordi Publishers.

Stallar, P., Spears, M., Montgomery, A. A., Phillips, R., \& Sayal, K. (2013). Self-harm in young adolescents (12 -16 years): On set and short-term continuation in a community sample. BMC Psychiatry, 13(1), 328-342. http://www.biomedcentral.com/1471$244 \mathrm{X} / 13 / 328$.

Steinberg, L., Vandell, D. L., \& Bronstein, M. H. (2011). Development: Infancy through adolescence. Belmont: Cengage Learning.

Tefera, B., \& Mulatie, M. (2014). Risky sexual behavior and identity construction among adolescents in Ethiopia. Journal of AIDS and HIV Research, 6(3), 65-71. doi: 10.5897/JAHR2013.0287.

Tefera, B., Ahemed, A., \& Fentahun, M. (2014). Selfregulatory behavior of adolescent students in Ethiopia: The case of Ayer Tena high school, Kolfe Keranio Sub City, Addis Ababa, Ethiopia. Science, Technology, and Arts Research Journal, 3(4), 172178. http://www.starjournal.org.

Thompson, R. A. (2011). Emotion and emotion regulation: Two sides of the developing coin. Emotion Review, 3(1), 53-61. doi: 10.1177/1754073910380969.

Tubbs, C. Y., Roy, K. M., \& Burton, L. M. (2005). Family ties: Constructing family time in low-income families. Family Process, 44(1), 77-91. doi:10.1111/ j.1545-5300.2005.00043.x.

Van As, N., \& Janssens, J. (2002). Relationship between child behavior problems and family functioning. Childcare in Practice, 5(1/2), 40-51. Retrieved from www.researchgate.net.

Vazsonyi, A. T., \& Huang, L. (2010). Where self-control comes from: On the development of self-control and its relationship to deviance over time. Journal of Developmental Psychology, 46(1), 245-257. doi: 10.1037/a0016538.

Vohs, K. D., \& Baumeister, R. F. (2004). Handbook of selfregulation: Research, theory, and application $\left(3^{\text {rd }}\right.$ Ed). New York: The Guilford Press.

Zimmermann, P., \& Iwanski, A., (2014). Emotion regulation from early adolescence to emerging adulthood and middle adulthood: Age differences, gender differences, and emotion-specific developmental variations. International Journal of Behavioral Development, 38(2) 182-194. doi: $10.1177 / 0165025413515405$. 